\title{
Immunohistochemical expression of HER-2/NEU-CERBB-2 in patients with adenocarcinoma of the stomach
}

\section{Expressão imunoistoquímica do HER-2/NEU-CERBB-2 em pacientes com adenocarcinoma do estômago}

\author{
Fernando K Cirne-Lima, MS'; Aline de Souza Rosa, BSc²; Jane M U Kulczynski, MD³; Diego S Mattana, BSc ${ }^{2}$;

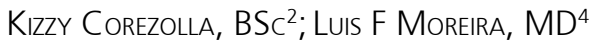

\section{A B S T R A C T}

\begin{abstract}
Objectives: To determine the prevalence of Her-2/Neu-cerbb-2 in the gastric mucosa of patients with gastric adenocarcinoma in a brazilian patient group. Methods: The immunohistochemical expression of Her-2/Neu was studied in 37 formalin-fixed paraffinembedded tissue sections. Results: The immunohistochemical reaction produced by the anti-HER-2/Neu antibody was positive in two cases $(5.4 \%)$. Conclusion: The low prevalence of Her-2/Neu observed in these southern brazilian cases is probably due to the great number of poorly differentiated cancers in this serie.
\end{abstract}

Key words: Stomach neoplasms. Oncogenes. Immunohistochemistry.

\section{INTRODUCTION}

G astric cancer is one of the most common solid tumours, being the second leading cause of cancer death worldwide, after lung cancer ${ }^{1,2}$. It is the most frequent cancer in Japan, with an incidence of approximately 100 cases per 100.000 inhabitants. It is also one of the most important cancers in developing countries in Asia, Africa and Latin America $^{3}$.

It is already known that different genetic pathways lead to intestinal or diffuse histological types of gastric cancer. Changes in specific genes which play important roles in several cellular functions such as adhesion, signal transduction, differentiation or DNA development and repair have been identified ${ }^{4}$.

Her2/Neu or CerbB-2 is a member of the HER family of growing factors (EGFR, erbB-2, erbB-3 and erbB-4) that have intrinsic protein tyrosine kinase activity, and its increased activity is the assumed mechanism of cell transformation ${ }^{5,6}$. These genes have been studied in many tumours and are generally associated with an unfavourable prognosis.

Despite, better operative techniques and the use of multimodal therapies, gastric cancer still has a poor prognosis. The understanding of structure and function of genes associated with gastric cancer is essential to establish methods for tumour diagnosis before invasion and dissemination, to develop new treatments and to evaluate the efficacy of therapeutic and preventive interventions ${ }^{4}$.

Distinct efficacy and toxicity of traditional cancer therapies have led to the development of new target-based agents. Members of the HER family are attractive therapeutic targets because they are over-expressed and/or uncontrolled in many solid tumours ${ }^{7}$. Activation of EGFR triggers a network of signalling processes that promote tumour cell proliferation, migration, adhesion, and angiogenesis, and a decrease in apoptosis. Therefore, inhibition of HER family members could prevent oncogenesis ${ }^{8}$.

Two anti-HER-2 monoclonal antibodies (MAbs), Trastuzumab (Herceptin; Genetech, Inc, South San Francisco) and Pertuzumab (2C4), have been developed. The former has been showing good results in metastatic breast tumours overexpressing HER-2.

Based on literature reports on overexpression of HER-2/Neu in many human tumours, including gastric cancer, and the good response of advanced breast cancer to a specific monoclonal anti-HER-2 antibody, the authors decided to investigate the immunohistochemical expression of this oncogene in a group of patients of the south of Brazil with gastric cancer, in an attempt to determine specific susceptible population for the possible use of inhibitors in the future.

\section{METHODS}

Retrospectively, 37 cases of patients with gastric adenocarcinomas who underwent surgical resection in the Tenth Infirmary of General Surgery of the Santa Casa de Porto Alegre between 2001 and 2003, following the eligibility criteria of the study, were studied.

From Federal University of Rio Grande do Sul (UFRGS); Post-Graduate Program of Surgery; Hospital de Clínicas de Porto Alegre; Pathology Unit, Porto Alegre, RS, Brasil.

1. Master of Surgery, Post-Graduate Program of Surgery, Doctorate fellow; 2. Bachelor of Science, Medicine, Research fellow; 3. Medicine Doctorate, Associate Professor of Pathology; 4. Medicine Doctorate, Associate Professor of Surgical Oncology. 


\section{Immunohistochemistry}

The immunohistochemical analyses used the "anti-human c-erbB-2 oncoprotein" (Dakocytomation -CA, USA) antibodies, that recognize the HER-2/Neu oncogene.

Tumour tissue sections were tested for cerbB-2 expression by the routine immunohistochemistry of the Pathology Service of the University Hospital (Hospital de Clínicas de Porto Alegre), using the primary antibodies previously described. After deparaffinisation and rehydration, antigenic recovery was performed in a microwave oven with citrate buffer. After, peroxidase was blocked to avoid endogenous peroxidase activity as well of other proteins; the slides were then incubated in a moist and dark chamber for $1 \mathrm{~h}$ to $2 \mathrm{~h}$ with the primary antibodies anti-cerbB-2 (Dako) diluted at 1:200 in PBS. The expression of the antibodies was performed by a subsequent incubation with the $A B C$ complex (LSAB kit-Dako); and the final reaction product was visualized by using the diaminobenzidine (DAB) as a chromogen. The counter-staining was performed with Harris Haematoxyline. A cerbB-2 positive breast adenocarcinoma was used as positive control for cerbB-2.

The slides were analyzed following a score of 0 to $3+$, where 0 , meant completely negative; $1+$ weakly positive; $2+$ moderately positive; and $3+$, strongly positive. The staining considered positive was at the membrane site. The cytoplasmic staining was noted, but not considered. The authors followed the herceptest score (Table 1) as provided by the manufacturer.

Slides not showing membrane staining were considered 0 , including those ones showing cytoplasmic staining. Those slides showing weak membrane staining in less than $10 \%$ of tumour cells were considered $1+$. Those ones with weak to moderate staining in more than $10 \%$ of cells were considered $2+$, and those showing strong membrane staining in more than $10 \%$ of the tumour cells were considered $3+$.

The scores 0 e $1+$ were classified as negative for HER-2/Neu. The scores 3+ and 4+ were classified as positive. Statistical analyses were performed considering mean, percentages, standard deviations and standard errors or chisquare test where appropriate. A $p<0.05$ was considered significant for a confidence interval of $95 \%$.

\section{RESULTS}

Twenty patients (54\%) were male and $17(46 \%)$ female. Age ranged from 33 to 85 years, with an average of 59.4 (sd 13); and median value of 62 years. Median lymph nodes and positive lymph nodes dissected were 15.8 (ranging 0 to 43 ) and 5 (ranging 0 to 20), respectively.

The immunohistochemical reaction produced by the anti-HER-2/Neu antibody was positive in only two cases (5.4\%) and negative in $35(94.6 \%)$ cases. Only one case was considered $1+$ and in $4(10.8 \%)$ there was only cytoplasmic staining. Clinical and pathologic characteristics are shown on table 2 . Figure 1 shows the positive sample control for CerbB-2 and figure 2 shows a positive case for CerbB-2.

Table 2 - Clinical and pathological features.

\begin{tabular}{|c|c|c|}
\hline Characteristics & $\mathrm{n}$ & Percent \\
\hline gender male/female & 20:17 & $54: 46$ \\
\hline \multicolumn{3}{|l|}{ Tumor site } \\
\hline Antrum/pyloro & 23 & 62 \\
\hline Body/fundus & 5 & 13.5 \\
\hline Fundus/cardia & 4 & 10.8 \\
\hline Cardia & 2 & 5.4 \\
\hline Antrum/body & 2 & 5.4 \\
\hline Linitis & 1 & 2.7 \\
\hline \multicolumn{3}{|l|}{ Surgical procedure } \\
\hline Partial gastrectomy & 24 & 65 \\
\hline Total gastrectomy & 11 & 30 \\
\hline Esophago-gastrectomy & 2 & 5 \\
\hline \multicolumn{3}{|l|}{ Histological type } \\
\hline diffuse & 22 & 59.5 \\
\hline intestinal & 13 & 35.1 \\
\hline combined & 2 & 5.4 \\
\hline \multicolumn{3}{|l|}{ Histological grade } \\
\hline Poorly differentiated (G3) & 34 & 91.9 \\
\hline Moderately differentiated & $(G 2) \quad 3$ & 8.1 \\
\hline \multicolumn{3}{|c|}{ TNM staging } \\
\hline la & 3 & 8.2 \\
\hline $\mathrm{lb}$ & 2 & 5.4 \\
\hline$\|$ & 3 & 8.2 \\
\hline IIla & 10 & 27 \\
\hline IIIb & 11 & 29.7 \\
\hline IV & 6 & 16.2 \\
\hline \multicolumn{3}{|l|}{ Immunohistochemistry } \\
\hline HER-2/neu & 2 & 5.4 \\
\hline EGFR & 0 & 0 \\
\hline
\end{tabular}

Table 1 - Classification of cerbB-2 expression determined by the herceptest (Dako) immunochemical method.

\begin{tabular}{|c|c|c|}
\hline SCORE & Expression & Staining Pattern \\
\hline 0 & Negative & No staining is observed, or membrane staining is less than $10 \%$ of the tumor cells. \\
\hline $1+$ & Negative & $\begin{array}{l}\text { A faint barely perceptive membrane staining is detected in more than } 10 \% \text { of the tumor cells. The cells } \\
\text { are only stained in part of the membrane. }\end{array}$ \\
\hline $2+$ & Positive & A weak to moderate complete membrane staining is observed in $10 \%$ of the tumor cells. \\
\hline $3+$ & Positive & A strong complete membrane staining is observed in more than $10 \%$ of the tumor cells. \\
\hline
\end{tabular}

Adapted from Dutra AP, et al. C-erbB-2 expression and nuclear pleomorphism in canine mammary tumours 9 . 


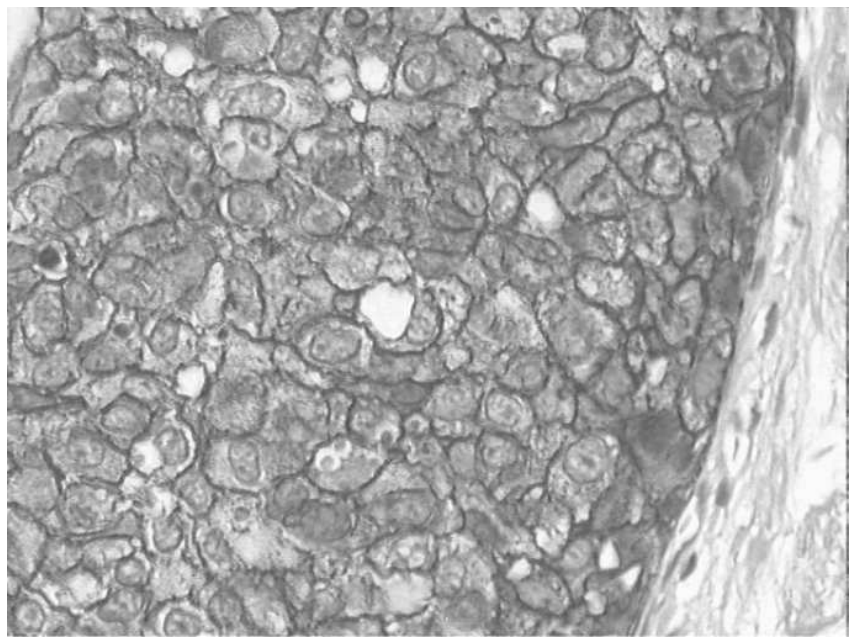

Figure 1 - Imunohistochemistry positive control slide for CerbB-2 (200x).

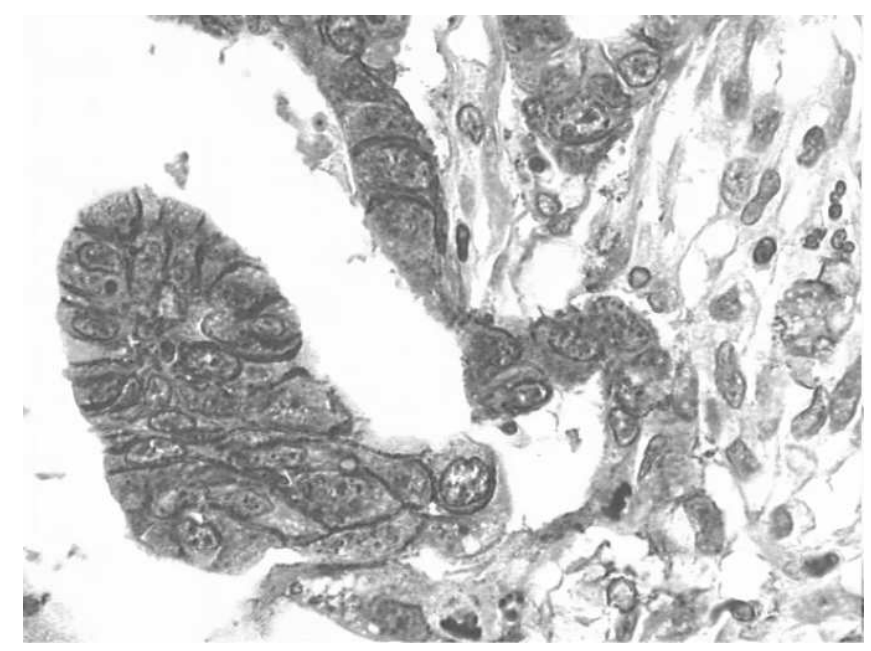

Figure 2 - Imunohistochemistry positive gastric adenocarcinoma sample for CerbB-2 (200x).

\section{DISCUSSION}

Despite its considerable decrease over the second half of the 20th century, gastric adenocarcinoma is still a worldwide health care problem. It is the second most deadly malignant tumour in the world. Approximately 876.000 individuals are diagnosed with the disease and almost 649.000 individuals die from gastric cancer every year ${ }^{10}$. For 2008, the National Institute of Cancer of Brazil (INCA) predicts an overall estimate of at least 22.000 new cases of the disease, and approximately 1600 cases for the State of Rio Grande do Sul, southern Brazil ${ }^{11}$.

In most countries the disease is usually diagnosed when has already invaded the muscularis propria, stage in which 5-year survival rates are less than 20\%. This unfavourable prognosis has not changed over the last decades, despite better operative techniques, or adjuvant chemotherapy and radiotherapy. The curable cases are generally tumours with early diagnosis that have not yet spread by lymphatic or vascular means. Prevention and early diagnosis seem to hold the greater hopes for disease control $^{10}$.
Distinct efficacy and toxicity of traditional cancer therapies have led to the development of new target-based agents. HER family genes are attractive therapeutic targets because they are over-expressed and/or show some degree of dysfunction in many solid tumours ${ }^{7}$. Moreover, there are specific anti-her antibodies already in use (Trastuzumab), as well as in different levels of clinical trials (pertuzumab, Cetuximab, Abx-EGF, h-R3, ertolinib e genfitinib) ${ }^{8}$.

In the present study the authors investigated the immunohistochemical expression of HER-2/Neu or cerbB-2 in 37 patients with gastric adenocarcinoma from southern Brazil (Rio Grande do Sul State). The over-expression of this oncogene has been the issue of several studies over the last decade. There is a wide variability of their expression worldwide ranging from $8 \%$ and $62 \%$ for Her-2/Neu. Recently a study from Switzerland reported $4.9 \%$ her-2/ neu positivity by immunohistochemistry ${ }^{12}$. Until the writing of the present manuscript the authors were unaware of or were able to retrieve any similar studies involving brazilian populations at risk for gastric cancer.

The variability of cerbB-2 studies in gastric cancer may be explained either by truly genetic variations between different tumours or by the diagnostic method used. The most reliable results are from methods at protein level detection (RT-PCR, FISH, quantitative PCR), but costs turn them unavailable for broaden use in developing countries such as Brazil. The most used method for cerbB-2 detection is still immunohistochemistry. The College of American Pathologists published in 2002 an issue comparing immunohistochemistry and FISH analyzes for cerbB-2 in breast cancer involving several american laboratories. FISH results showed a remarkable concordance between different laboratories. Immunohistochemistry showed substantial variability ${ }^{13}$. On the other hand, immunohistochemistry technique is easier, less expensive, and can be carried out in most pathology laboratories being already routinely used by several laboratories for oncogene and tumour suppressor gene analyses throughout Brazil. The authors believe that an immunohistochemistry technique performed by a skilful pathologist and reviewed by a second one is a reliable method for oncogene expression analyses. Recently, a paper showed close association between Her-2/neu amplification and overexpression in human tumours of non-breast origin ${ }^{12}$ which further corroborates immunohistochemistry reliability. Even though, many immunohistochemical cerbB2 papers show results using the herceptest score, a reliable comparison seems to be difficult because usually how scores were determined have not been clearly specified. Most of these studies do not show how positive or negative slides are specifically defined.

Regarding other tumours, many studies have demonstrated good results with anti-EGFR and anti-HER-2/ Neu drugs. In a randomized clinical trial with 469 patients with metastatic breast cancer positive to HER-2 overexpression a $50 \%$ overall response rate was observed for patients assigned to trastuzumab plus chemotherapy treatment arm as compared with 35\% for those allocated to the chemotherapy arm only; and the median survival 
period was 25 months favouring the combination ${ }^{14}$. Recently, trastuzumab was shown to be effective as adjuvant therapy in Her-2 positive breast cancer patients too ${ }^{12}$. Trastuzumab showed good response of HER-2+ pancreatic cell lines in an experimental study ${ }^{15}$. Studies with anti-EGFR drugs in non-small cells lung cancer, head and neck squamous cell carcinoma and colorectal carcinomas have demonstrated promising results ${ }^{8}$.

The low prevalence of Her-2/neu overexpression in this study can be perhaps explained by a sample bias. Uchino ${ }^{16}$ detected $2 \%$ positive staining of CerbB- 2 protein in poorly differentiated gastric tumours, and Tsujimoto ${ }^{17}$ found no amplification of C-erbB-2 gene in undifferentiatedtype cancers by Western Blot. This paper had $92 \%$ of poorly differentiated cancers and only $8 \%$ of moderately differentiated cancers. Authors as Becker ${ }^{18}$ and Kameda et al. ${ }^{19}$ described no Her-2/Neu gene amplification in diffuse type gastric cancer and $20 \%$ of amplification in intestinal type. In this sample it was presented 11 intestinal, 2 mixed and 22 diffuse type carcinomas.

In conclusion the authors found a low prevalence (5.4\%) of HER-2/Neu overexpression in these 37 gastric cancer patients from southern Brazil. However, the poor prognosis of gastric cancer with the currently available therapies, and the good and promising response of certain tumours to specific monoclonal antibodies anti-HER-2/Neu, must encourage the search for this oncogene in other gastric cancer populations, as well as, the development of more clinical trials with anti-Her drugs in cerbB-2 positive individuals.

\section{R E S U M O}

Objetivo: Determinar a prevalência do Her-2/Neu-CerbB-2 na mucosa de pacientes com adenocarcinoma de estômago em um grupo de doentes brasileiros. Métodos: A expressão imunoistoquímica do Her-2/Neu foi estudada em 37 amostras de tecidos fixados em formalina e embebidos em parafina. Resultados: A reação imunoistoquímica produzida pelo anticorpo HER-2/Neu foi positiva em dois pacientes (5.4\%). Conclusão: A baixa prevalência Her-2/Neu observada neste grupo de pacientes é provavelmente devida ao grande número de tumores pouco diferenciados encontrados nesta série.

Descritores: Neoplasias gástricas. Oncogenes. Imunoistoquímica.

\section{REFERENCES}

1. Kelsen D. Introduction: Gastric cancer. Semin Oncol 1996; 3: 279-80

2. Parkin DM, Pisani P, Ferlay J. Estimates of the worldwide frequency of eighteen major cancers. Int J Cancer. 1993; 54(4):594-606.

3. Fuchs CS, Mayer RJ. Gastric carcinoma. N Eng J Med. 1995; 333(1):32-41.

4. Becker KF, Keller G, Hoefler $H$. The use of molecular biology in diagnosis and prognosis of gastric cancer. Surg Oncol. 2000; 9(1):511.

5. Klapper LN, Glathe S, Vaisman N, Hynes NE, Andrews GC, Sela M, Yarden $Y$. The ErbB-2/HER-2 oncoprotein of human carcinomas may function solely as a shared coreceptor for multiple stromaderived growth factors. Proc Natl Acad Sci USA. 1999; 96(9):49955000.

6. Ruddon RW. Genetic alterations in cancer cells. In: Ruddon RW. Cancer biology. $3^{\text {rd }}$ ed. Oxford: Oxford University Press; 1995.

7. Baselga J. Why the epidermal growth factor receptor? The rationale for cancer therapy. Oncologist. 2002; 7 Suppl 4: 2-8.

8. Arteaga C. Targeting HER1/EGFR: a molecular approach to cancer therapy. Semin Oncol. 2003; 30(Suppl 7): 3-14.

9. Dutra AP, Granja NV, Schmitt FC, Cassali GD. c-erbB-2 expression and nuclear pleomorphism in canine mammary tumors. Braz J Med Biol Res. 2004; 37(11):1673-81. Epub 2004 Oct 26.

10. Correa P. Is gastric cancer preventable? Gut. 2004; 53(9):1217-9.

11. INCA- Ministério da Saúde do Brasil. Captured in 18/12/2008. http:/ /www.inca.org.br/epidemiologia/estimativa.

12. Tapia C, Glatz K, Novotny H, Lugli A, Horcic M, Seemayer CA. Close association between HER-2 amplification and overexpression in human tumors of non-breast origin. Moder Pathology 2007; 20(2):192-8.

13. Cell Markers and Cytogenetics Committees College of American Pathologists. Clinical laboratory assays for HER-2/neu amplification and overexpression: quality assurance, standardization, and proficiency testing. Arch Pathol Lab Med. 2002; 126(7):803-8.
14. Leyland-Jones B. Trastuzumab: Hopes and realities. Lancet oncol. 2002; 3(3):137-44.

15. Huang ZG, Buchsbaum DJ, Raisch K, Bonner JA, Bland KI, Vickers SM. Differential responses by pancreatic carcinoma cell lines to prolonged exposure to Erbitux (IMC-C225) anti-EGFR antibody. J Surg Res. 2003; 111(2):274-83.

16. Uchino S, Tsuda H, Maruyama K, Kinoshita T, Sasako M, Saito T, et al. Overexpression of C-ERBB-2 protein in gastric cancer. Its correlation with long-term survival of patients. Cancer. 1993; 72(11):3179-84.

17. Tsujimoto $H$, Sugihara $H$, Hagiwara A, Hattori T. Amplification of growth factor receptor genes and DNA ploidy pattern in the progression of gastric cancer. Virchows Arch. 1997; 431(6):383-9.

18. Becker KF, Keller G, Hoefler $\mathrm{H}$. The use of molecular biology in diagnosis and prognosis of gastric cancer. Surg Oncol. 2000; 9(1):5-11.

19. Kameda T, Yasui W, Yoshida K, Tsujino T, Nakayama H, Ito M, et al. Expression of ERBB2 in human gstric carcinomas: relationship between 185 ERBB2 expression and the gene amplification. Cancer Res. 1990; 50(24):8002-9.

Recebido em 02/10/2008

Aceito para publicação em 04/12/2008

Conflito de interesse: nenhum

Fonte de financiamento: This work was partially supported in grant by the Brazilian Council on Post-Graduation (CAPES PRODOC 2003).

\section{Como citar esse artigo:}

Cirne-Lima FK, Rosa AS, Kulczynsk JMU, Moreira LF. Immunohistochemical expression of HER-2/neu-CERBB-2 in patients with adenocarcinoma of the stomach. Rev Col Bras Cir. [periódico na Internet] 2009; 36(2). Disponível em URL: http://www.scielo.br/rcbc

\section{Correspondence to:}

Luis F. Moreira

e-mail: bruce@cpovo.net 